\title{
Announcement - a new era for Gold Bulletin
}

I want to inform you of a very significant change to the publication of Gold Bulletin due to be implemented from 1st January 2011.

As you may be aware Gold Bulletin dates back to 1968, when the first issue was published by the Chamber of Mines in South Africa. Since 1987 the World Gold Council (WGC) has published the journal. A major change occurred in 2005 when Gold Bulletin became an e-journal and was published on its own website, www.goldbulletin.org. This change enabled the journal to increase in size and reach a larger and growing readership. The archive of back issues was also placed on the website, so enabling ready access to the complete set of volumes published to date. During recent years the journal has achieved some very impressive Impact Factors (IF). Our current IF is 2.324.

As the size of the journal has increased we have found that the costs of producing Gold Bulletin 'in-house' at World Gold Council have also substantially increased. We have also found that the world of academic publishing has become increasingly complex and specialised; producing a journal that meets current demands has become very time consuming for the WGC team, who manage many other activities alongside Gold Bulletin.

With these challenges in mind we are announcing that WGC has signed an agreement with Springer www.springer.com to facilitate the publication of Gold Bulletin from the end of this year. The journal will be published by Springer through the sponsorship of WGC. Importantly, the journal will:

- remain a free, peer reviewed, open access journal

- continue to completely focus on the science and industrial applications of gold

- benefit from Springer's wider distribution channels and academic publishing expertise
I confirm that I will be remaining as Editor of the journal next year and will be sharing this task with Dr Trevor Keel (who also works at WGC). He will be joining me as Associate Editor, with a particular focus on the nanotechnology coverage in the journal. For those of you that do not know Trevor, he has extensive experience in pharmaceutical research having spent a number of years working for GlaxoSmithKline, the leading healthcare company. As such he has particular interest in the use of gold in the fields of medicine, diagnostics and nanotechnology.

Under the new arrangements for Gold Bulletin, Springer will be largely responsible for the technical production and editing of the publication and so, with sadness I confirm that Dr Patricia Harris will not be continuing in her role as Technical Editor at the end of 2010. I know that many of you have had considerable dealings with Dr Harris and will wish to thank her for a great contribution to the running of the journal over many years.

Further details on the launch of the new look for Gold Bulletin will be announced in due course.

If you have any comments on this announcement we will be pleased to receive them.

\section{Richard Holliday}

Editor, Gold Bulletin

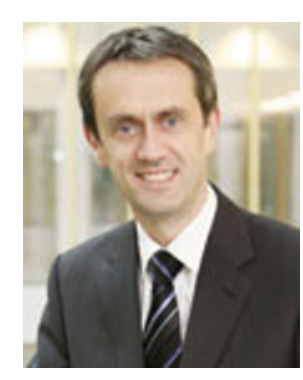

